\title{
The clinical characteristics of fungal keratitis in eyes after Descemet's stripping and automated endothelial keratoplasty
}

This article was published in the following Dove Press journal:

Clinical Ophthalmology

9 September 2014

Number of times this article has been viewed

\author{
Kaoru Araki-Sasaki ${ }^{1,2}$ \\ Atsuko Fukumoto' \\ Yasuhiro Osakabe ${ }^{3}$ \\ Hideya Kimura' \\ Shinichiro Kuroda' \\ 'Nagata Eye Clinic, Nara, Japan; \\ 2Department of Ophthalmology, \\ Japan Community Health Care \\ Organization, Hoshigaoka Medical \\ Center, Osaka, Japan; ${ }^{3}$ Department of \\ Molecular Pathology, Tokyo Medical \\ University, Tokyo, Japan
}

\begin{abstract}
The purpose of this study was to describe the clinical characteristics of fungal keratitis caused by Candida albicans in an eye after Descemet stripping automated endothelial keratoplasty (DSAEK). A 72-year-old male with a history of three trabeculectomies, cataract surgery, and two DSAEK procedures developed a corneal ulcer in his right eye two years after his last DSAEK. Fungal keratitis was most likely related to the immunosuppressive conditions that occurred due to the previous operations, the continuous use of steroid eye drops, and the use of disposable soft contact lenses. A smear and culture from the ulcer detected Candida albicans. Slit-lamp examination showed the characteristic feature was the presence of interface infiltrates located between the host and the graft cornea and in the enlarged area around the ulcer. Two weeks after intense antimycotic treatments with voriconazole, miconazole, and natamycin, perforation of the cornea occurred and further therapeutic penetrating keratoplasty was required. Histological analysis revealed an accumulation of infiltrated cells and fibrotic tissue. The poor prognosis for fungal keratitis that occurs in eyes after undergoing DSAEK may be related to the rapid expansion of inflammatory cells through the interface between the host and the graft. In eyes that develop fungal keratitis after DSAEK, special attention should be paid to the possibility that perforation could occur in these patients.
\end{abstract}

Keywords: DSAEK, Candida albicans, fungal keratitis, keratomycosis, post-operative infection

\section{Introduction}

Descemet stripping automated endothelial keratoplasty (DSAEK) has proven to be an excellent method for treating bullous keratopathy. However, since the occurrence of infectious keratitis can be related to non-physiological conditions, patients undergoing DSAEK need to be carefully evaluated after the procedure. After the DSAEK procedure, the corneal graft is weakly attached to the host cornea with the help of the pump function of endothelial cells. Use of anterior ultra-high-resolution optical coherence tomography (OCT) makes it possible to detect the interface between the host and the graft at all times.

When infectious keratitis occurs after DSAEK, the most commonly isolated causative organism has been reported to be Candida albicans. ${ }^{1,2}$ Recent development of newer antimycotic agents has led to a much better prognosis for patients with fungal keratitis caused by $C$. albicans. In particular, voriconazole has been shown to have an especially good sensitivity for C. albicans isolated from fungal keratitis. ${ }^{3}$ However, most of the fungal keratitis that occurs in eyes after the DSAEK procedure requires that patients undergo further surgical treatments. Despite the good sensitivity of the antimycotic agents, these patients have been reported to have a poor prognosis. ${ }^{4-9}$
Correspondence: Kaoru Araki-Sasak Nagata Eye Clinic, I 147, Kitayamada, Horai-cho, Nara 63I-0844, Japan

Tel +81742452230

Fax +8I 74245080

Email sasakis@sa2.so-net.ne.jp 
In order to better understand this condition, our current study further examined the specific clinical characteristic features of fungal keratitis found in eyes after the DSAEK procedure.

\section{Case report}

A 72-year-old man began to complain of ocular pain, discharge, and conjunctival injection in his right eye in October 2012. The patient had a history of cataract surgery and three filtering surgeries due to secondary glaucoma with uveitis in his right eye. Due to bullous keratopathy in the same eye, he had previously undergone DSAEK in 2008, and again in 2010. During this time, he was continuously prescribed $0.1 \%$ predonisolone eye drops four times daily, and he sometimes used disposable soft contact lens (DSCL) to help resolve the pain. His general history included diabetes mellitus and hypertension. At his first visit to the Nagata Eye Clinic, in October 2012, slit-lamp examination demonstrated a small, whitish infiltrate, starting at the superficial stroma and continuing until one-third the stromal depth at the 8 o'clock area (Figure 1). Since an infectious corneal ulcer was suspected, the doctor on call prescribed topical $1.5 \%$ levofloxacin eye drops. When the patient returned to the clinic on the ninth day after his initial visit, he was still continuously wearing the DSCL. Slit-lamp examination showed that there was an enlarged deep corneal stromal infiltrate (Figure 2). A smear of corneal scraping revealed yeast that was later identified as C. albicans (Figure 3). The characteristic finding observed during the slit-lamp examination was the presence of interface infiltrates between the host cornea and the graft around the corneal ulcer. Topical and general antifungal therapy was started, which included

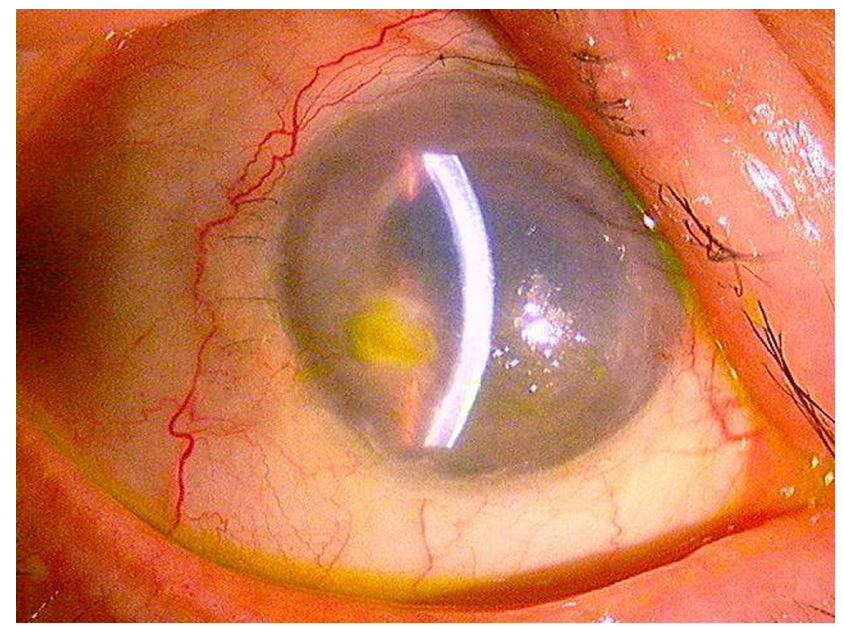

Figure I Diffuse lamp examination photograph taken at the first visit. Small whitish infiltrates are observed in the superficial corneal stroma at the 8 o'clock area.

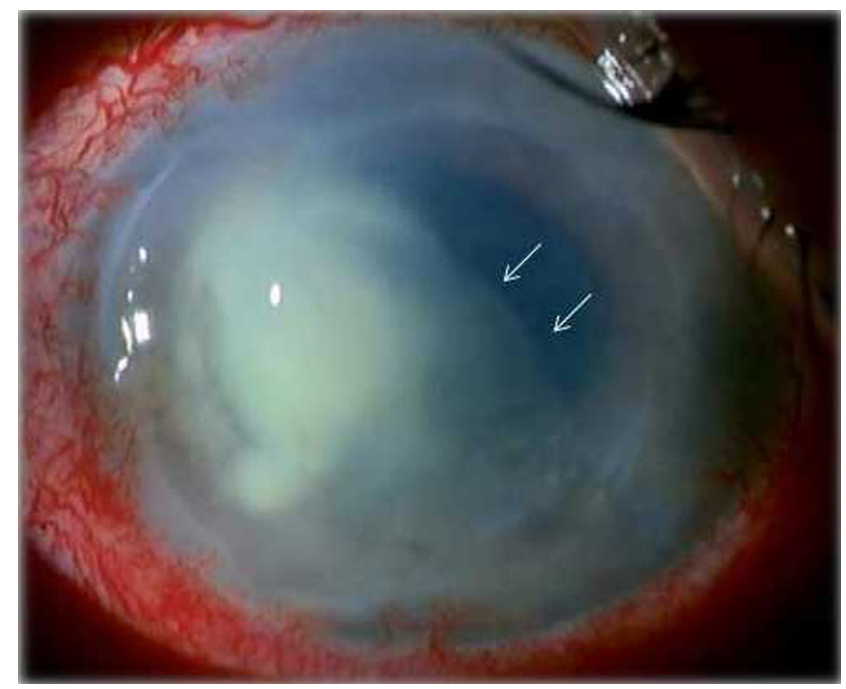

Figure 2 At 9 days after the patient's first visit, characteristic interface infiltration was observed (arrow) between the graft and host cornea, which is enlarged around the ulcer and within the DSAEK area.

Abbreviation: DSAEK, Descemet stripping automated endothelial keratoplasty.

$1 \%$ voriconazole and $0.1 \%$ miconazole eye drops every hour, application of natamycin ointment prior to sleep, $1.5 \%$ levofloxacin four times daily, and $1 \%$ atropine eye drops once daily. Additionally, we continued an intense antimycotic treatment of $400 \mathrm{mg} /$ day of oral voriconazole and an intrastromal injection of voriconazole. The day after the injection, a blood influx from the neovascularization was observed in the interface space between the host cornea and the graft (Figure 4). Two days later, perforation of the cornea occurred at the temporal site with the shallow anterior chamber. Therapeutic penetrating keratoplasty, with removal of the intraocular lens and anterior vitrectomy, was performed. During this procedure, detachment of the graft from the host cornea was observed. Subsequently, we continued both the topical and systemic antifungal therapy; one month later there

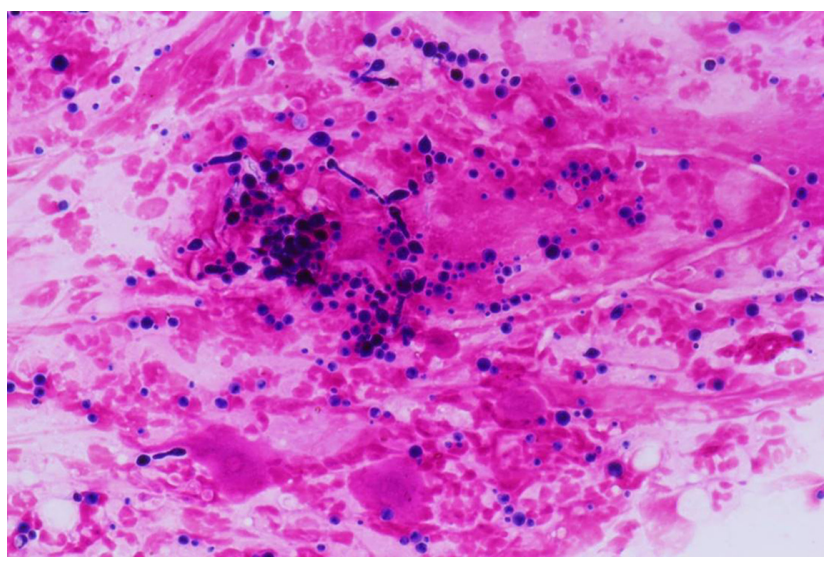

Figure 3 Smear of the corneal scraping that shows budding yeasts. 


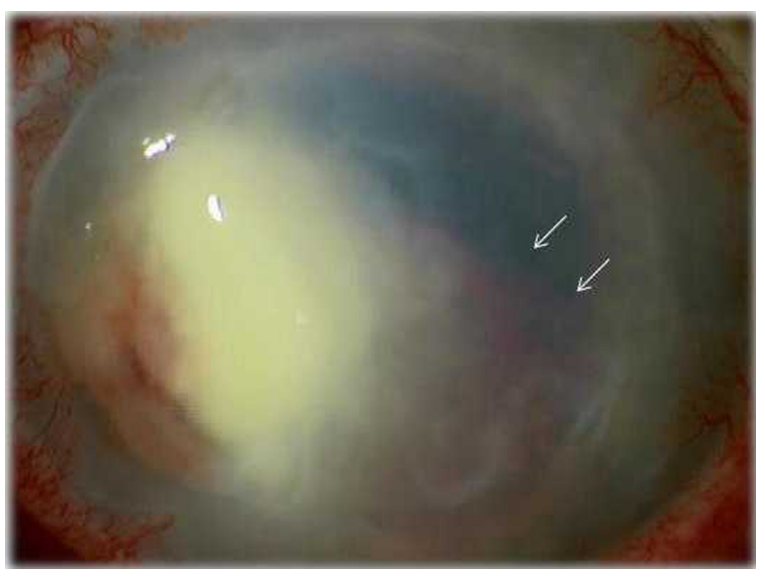

Figure 4 Blood coagulation was observed within the interface between the graft and host cornea (arrows) on the day after an intrastromal injection of the antimycotic agent.

was clinical resolution of the infection. Histopathological examination of the excised corneal specimen revealed that there was an accumulation of numerous inflammatory cells and fibrous tissue at the interface between the graft and host cornea (Figure 5). Grocott staining demonstrated a few fungal organisms found in the tissue (Figure 5, inset).

\section{Discussion}

Recent improvement in antimycotic agents has made it possible to successfully treat fungal keratitis caused by $C$. albicans. However, despite the effectiveness of these antimycotic agents, a poor diagnosis remains in patients who develop fungal keratitis after DSAEK. ${ }^{4-8}$ Although we did not perform any sensitivity tests for the antimycotic agents used in the current case, empirical data suggest that both voriconazole and miconazole are effective against C. albicans. ${ }^{3}$

During the early observation period in this patient, slit-lamp examination revealed the presence of interface infiltrates between the graft and the host cornea. Although endothelial plaque is a characteristic phenomenon seen in fungal keratitis, we were able to distinguish the interface infiltrates from the endothelial plaque. Based on the organisms and inflammatory cells that we observed during the operation, we speculate that these cells and organisms can easily spread through the interface space between the host cell and the graft in eyes that have undergone the DSAEK procedure. Thus, this may be one of the reasons for the poor prognosis that is seen in these patients. Although delayed diagnosis and intrastromal injection could be the reason for the perforation in our current patient, previous reports have suggested that fungal keratitis that occurs after DSAEK might develop within the deep corneal stroma. ${ }^{3-7}$ Therefore, due to a tendency of easy perforation, it is likely that DSAEK-treated eyes will need post-surgical treatments more frequently than non-DSAEK-treated eyes. Unfortunately, these previous reports did not present any clinical photographs that clearly showed the interface infiltration. In the current case, we believe that the organisms could be found during the patient's first visit in October 2012 were due to a combination of the immunosuppressive condition related to the prednisolone eye drops, the postoperative condition, and continuous DSCL use. We do not believe that the organisms were transmitted from donor to host during the DSAEK operation. Nonetheless, the phenomenon in which the organisms and inflammatory cells spread in the interface space can be observed in eyes that develop primary and secondary fungal keratitis after DSAEK.

Our current findings also indicated that any injected liquid will flood into the interface space, due to the weak attachment of the graft. Thus, intrastromal injection should be avoided when fungal keratitis occurs in an eye after DSAEK.

In order to ensure a better prognosis for this disease and to determine the most appropriate treatment for fungal keratitis

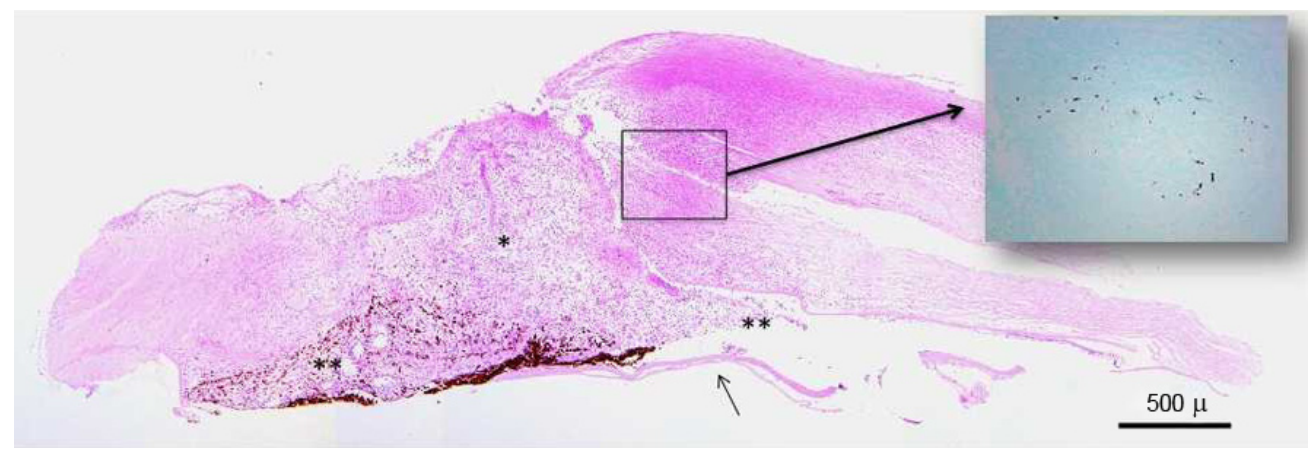

Figure 5 Histological analysis of the excised cornea. Descemet's membrane was detached due to the pathological process (arrow). Inflammatory cells and fibrin are observed filling the perforated area $\left(^{*}\right)$ and spreading into the surrounding tissue $\left(^{* *}\right)$. Grocott staining (inset) indicates the presence of a few fungal organisms. 
that occurs in eyes after DSAEK, we will need to accumulate more data from further studies.

\section{Conclusion}

Interface infiltrates between the donor and host cornea around a corneal ulcer are a characteristic feature of fungal keratitis that occurs in eyes after DSAEK. Due to the possibility of corneal perforations, special attention needs to be paid to patients with fungal keratitis, especially in eyes that have undergone DSAEK.

\section{Acknowledgment}

The authors would like to thank Dr Miyo Matsumura for her useful advice on carrying out this study.

\section{Disclosure}

The authors report no conflicts of interest in this work.

\section{References}

1. Shulman J, Kropinak M, Ritterband DC, et al. Failed Descemet-stripping automated endothelial keratoplasty grafts: a clinicopathologic analysis. Am J Ophthalmol. 2009;148(5):752-759.

2. Zhang Q, Randleman JB, Stulting RD, et al. Clinicopathologic findings in failed Descemet stripping automated endothelial keratoplasty. Arch Ophthalmol. 2010;128(8):973-980.

Clinical Ophthalmology

\section{Publish your work in this journal}

Clinical Ophthalmology is an international, peer-reviewed journal covering all subspecialties within ophthalmology. Key topics include: Optometry; Visual science; Pharmacology and drug therapy in eye diseases; Basic Sciences; Primary and Secondary eye care; Patient Safety and Quality of Care Improvements. This journal is indexed on
3. Katsuragi S, Sata M, Kobayashi Y, et al. Antifungal susceptibility of Candida isolates at one institution. Med Mycol J. 2014;55(1):E1-E7.

4. Lee WB, Foster JB, Kozarsky AM, Zhang Q, Grossniklaus HE. Interface fungal keratitis after endothelial keratoplasty: a clinicopathological report. Ophthalmic Surg Lasers Imaging. 2011;42:e44-e48.

5. Koenig SB, Wirostko WJ, Fish RI, Covert DJ. Candida keratitis after Descemet stripping and automated endothelial keratoplasty. Cornea. 2009;28:471-473.

6. Kitzmann AS, Wagoner MD, Syed NA, Goins KM. Donor-related Candida keratitis after Descemet stripping automated endothelial keratoplasty. Cornea. 2009;28(7):825-828.

7. Ortiz-Gomariz A, Higueras-Esteban A, Gutiérrez-Ortega ÁR, Gonzáles-Méijome JM, Arance-Gil A, Villa-Collar C. Late-onset Candida keratitis after Descemet stripping automated endothelial keratoplasty: clinical and confocal microscopic report. Eur J Ophthalmol. 2011;21(4):498-502.

8. Chew AC, Mehta JS, Li L, Busmanis I, Tan DT. Fungal endophthalmitis after Descemet stripping automated endothelial keratoplasty - a case report. Cornea. 2010;29(3):346-349.

9. Shamra N, Agarwal PC, Kumar CS, Mannan R, Titiyal JS. Microbial keratitis after Descemet stripping automated endothelial keratoplasty. Eye Contact Lens. 2011;37(5):320-322.
PubMed Central and CAS, and is the official journal of The Society of Clinical Ophthalmology (SCO). The manuscript management system is completely online and includes a very quick and fair peer-review system, which is all easy to use. Visit http://www.dovepress.com/ testimonials.php to read real quotes from published authors. 